Mycologia, 96(6), 2004, pp. 1245-1252.

(C) 2004 by The Mycological Society of America, Lawrence, KS 66044-8897

\title{
Co-expression of two genes, a chitinase (chit42) and proteinase (prb1), implicated in mycoparasitism by Trichoderma hamatum
}

\author{
Johanna M. Steyaert ${ }^{1}$ \\ Bio-protection and Ecology Division, P.O. Box 84, \\ Lincoln University, Canterbury, New Zealand \\ Alison Stewart \\ National Centre for Advanced Bio-Protection \\ Technologies, P.O. Box 84, Lincoln University, \\ Canterbury, New Zealand \\ Marlene V. Jaspers \\ Margaret Carpenter \\ Hayley J. Ridgway \\ Bio-protection and Ecology Division, P.O. Box 84, \\ Lincoln University, Canterbury, New Zealand
}

\begin{abstract}
Mycoparasitism of fungal plant pathogens by Trichoderma species is a complex process that involves the production and co-ordinated secretion of cell-wall degrading enzymes. Genes implicated in mycoparasitism by Trichoderma atroviride contain motifs in the promoter region, designated MYRE1-MYRE4, that are proposed to act as binding sites for a global inducer of the mycoparasitic response. The aim of our study was to establish whether these motifs also were present in Trichoderma hamatum and whether the presence of these motifs could predict co-expression when $T$. hamatum was confronted by a pathogen. Using a combination of targeted, degenerate and inverse PCR, homologues of the mycoparasitismrelated genes ech42 (chit42), prb1 and lam1.3 (xbg1.3-110), which encode an endochitinase, proteinase, and $\beta$-1,3-glucanase, respectively, were cloned and sequenced from T. hamatum. Alignment of the promoter regions of the three genes revealed identical regions in the chit 42 and prb1 promoters, which were $6-9$ base pairs in length and conserved in position. Specifically, the regulatory motifs MYRE1-MYRE4 were fully conserved, together with a fifth motif, identified by this research. A substrate assay designed to investigate the response of these genes from T. harzianum and T. hamatum to a simple carbon source (glycerol) showed that, in contrast to chit42 and prb1, xbg1.3-110 was not expressed. Further comparison of the expression patterns of these three genes between $T$. harzianum and T. hamatum using the glycerol substrate assay showed that no
\end{abstract}

\footnotetext{
Accepted for publication May 27, 2004.

${ }^{1}$ Corresponding author. E-mail: steyaej1@lincoln.ac.nz
}

chit42 or prb1 expression could be detected in T. harzianum when it was grown under the same conditions as T. hamatum. This showed that the response of these genes to glycerol was species specific and that a single expression pattern for these genes was not common to all Trichoderma species. Confrontation assays were used to investigate the response of the three T. hamatum genes to the more complex substrate posed by the fungal pathogen Sclerotinia sclerotiorum. Once again gene expression analysis showed that both chit42 and prb1 were co-expressed and moderately induced during confrontation against Sclerotinia sclerotiorum. Although xbg1.3-110 previously had been implicated in mycoparasitism by $T$. harzianum, this study detected no xbg1.3-110 expression during confrontation between T. hamatum and S. sclerotiorum. These findings show that the MYRE1MYRE4 together with MYRE5 are present in two species of Trichoderma, T. atroviride and T. hamatum and that the presence of these motifs could predict coexpression in response to two carbon sources.

Key words: biocontrol, chit42, gene regulation, prb1, xbg1.3-110

\section{INTRODUCTION}

Biocontrol of plant pathogens is an essential component of sustainable agriculture. Trichoderma spp. are biocontrol agents of many economically important pathogens, such as species of Botrytis, Rhizoctonia and Sclerotinia. Control of these diseases by chemical pesticides is losing effectiveness due to enhanced degradation by soil microorganisms and growing resistance within pathogen populations (Jones and Stewart 2000). Trichoderma spp. commercially represent one-third of all fungal biocontrol agents of soil-borne fungal phytopathogens (Chernin and Chet 2002), and their prevalence as biocontrol agents has stimulated much research into the mechanisms underlying biocontrol, of which mycoparasitism is considered a major component.

The majority of reported biocontrol agents are isolates of T. harzianum or T. atroviride, from which 16 genes implicated in mycoparasitism have been sequenced (Benítez et al 1998, Kubicek and Penttilä 1998, Lorito 1998, Cohen-Kupiec et al 1999, Donzelli et al 2001). Transformation studies have demonstrat- 
ed a link between some mycoparasitism-related genes and biocontrol potential. Increased biocontrol activity has been attained by integrating multiple copies of the prb1 gene into the genome of $T$. atroviride (Flores et al 1997). Introduction of multiple copies of the endochitinase chit 33 in T. harzianum also resulted in increased biocontrol ability (Dana et al 2001). In contrast, no difference was observed between T. atroviride ech 42 overexpression mutants, deletion mutants and wild type (Carsolio et al 1999). Although expression of ech42 and secretion of ECH42 protein during in vitro confrontation with a host pathogen implicated a role for this gene in biocontrol (Carsolio et al 1994), recent diffusion studies have shown ech 42 to be involved in pathogen signalling (Kubicek et al 2001), suggesting a more regulatory role for this enzyme. Considerable attention also has focused on the $\beta$-glucanase genes because a large component of the fungal cell wall is composed of $\beta$ glucans and, therefore, it is likely that $\beta$-glucanases play a role in cell-wall degradation during mycoparasitism. Expression of the $\beta$-1,3-glucanase genes lam1.3 (Cohen-Kupiec et al 1999) and gluc78 (Donzelli et al 2001) from $T$. harzianum during confrontation have implicated a role for these genes in biocontrol.

The endochitinase gene ech 42 and alkaline proteinase gene $p r b 1$ have been characterized extensively from T. atroviride (Lorito et al 1996, Cortés et al 1998 [isolate previously referred to as T. harzianum, later reclassified as T. atroviride \{Kullnig et al 2001\}]), revealing many insights into the regulation of these genes. Carbon catabolite repression through binding of Cre1 to the promoter (Lorito et al 1996) is considered the major negative regulator of the mycoparasitic response. Nitrogen repression of prb1 more recently was demonstrated (Olmedo-Monfil et al 2002). Alignment of promoter sequence from $T$. atroviride ech 42 and prb1 with known transcription factor motifs has suggested other regulatory pathways, such as light-induced sporulation and stress. Both these stimuli induce ech42 and prb1 expression supporting involvement of transcription factor binding at BrlA and STRE motifs. Four putative binding sites, MYRE1MYRE4 (previously referred to as MYC, Carlos Cortés, pers comm), for an inducer of mycoparasitism have been suggested by alignment of the ech 42 and prb1 promoters (Cortés et al 1998). This has been supported by knockout studies of MYRE4, in which reduced ech 42 expression was apparent. In addition, a Cre1 motif overlapped MYRE3, from which a proposed mechanism for mycoparasitic induction was formulated, in which Cre1 binding must be relieved to allow binding of the mycoparasitism inducer (Lorito et al 1996).
Mycoparasitism is a process that most Trichoderma species use to attack and parasitize other fungi. Therefore, the molecular mechanisms underlying mycoparasitism-based biocontrol are likely to be highly conserved. This hypothesis is in agreement with taxonomic studies on relatedness of ech 42 homologues from multiple Trichoderma spp., which have shown this gene to be highly conserved throughout the genus (Lieckfeldt et al 2000). The current study is focused on a T. hamatum isolate that has undergone extensive field testing where it has shown a high degree of ability to control Sclerotinia diseases of vegetable crops during development for use as a commercial biocontrol agent (BCA) (Rabeendran 2000). In vitro assays have demonstrated that this isolate can mycoparasitize $S$. sclerotiorum. The aim of this study was to isolate and characterize three mycoparasitism-related genes from T. hamatum. Subsequent identification of regulatory motifs in the promoter region of these genes and analysis of expression patterns might provide evidence for regulatory pathways that either contrast or are similar to those reported in other Trichoderma species. This also might suggest putative molecular targets for manipulating genetic regulation in vivo as a mechanism of optimizing of T. hamatum biocontrol activity in the field.

\section{MATERIALS AND METHODS}

Fungal isolates and maintenance.-Trichoderma hamatum LU593 and T. harzianum LU678 were isolated from New Zealand soils and were identified by morphology and ITS1 sequencing. Sequences were compared to species neotypes (T. hamatum DAOM 167057, accession number Z48816; T. harzianum CBS 226.95, accession number AJ222720). The Sclerotinia sclerotiorum isolate G1 used in the direct confrontation assay was from Montana, USA, and has been identified on the basis of morphology. All Trichoderma spp. isolates were maintained and stored on potato-dextrose agar (PDA) (Beckton Dickson \& Co.) slopes. The S. sclerotiorum isolate was maintained on PDA and stored at $4 \mathrm{C}$ as dried sclerotia.

Cloning of the mycoparasitism-related genes.-Genomic DNA was isolated from all Trichoderma spp. isolates using the Genomag kit (Advanced Biotechnologies Ltd.) as per manufacturer's instructions. chit42 was amplified from $T$. hamatum LU593 using primers designed to a T. hamatum chit42 (ech42 homologue) sequence in GenBank (Tam-61, accession number U88560) (TABLE I). A segment of prb1 was isolated from $T$. hamatum LU593 and T. harzianum LU678 using primers, PRBAtrC-F and PRBAtrC-R (TABLE I), designed to the signal peptide region and exon 2 of prb1 (accession number M87518) from T. atroviride IMI206040. Inverse primers I-PRB-509 (5'-GCTTCTTGTGAGGGCTGC$\left.3^{\prime}\right)$ and I-PRB-1067 (5'-GGTGTTAACATTCTGTCGTC-3') 
TABLE I. Primers used to amplify mycoparasitism-related genes from T. hamatum LU593 and T. harzianum LU678

\begin{tabular}{|c|c|c|c|c|c|c|}
\hline Primer & Gene & Region & Species & Sequence $5^{\prime}-3^{\prime}$ & $\begin{array}{l}\text { Anneal } \\
\text { Tm. C }\end{array}$ & $\begin{array}{l}\text { Product } \\
\text { size }(\mathrm{kb})\end{array}$ \\
\hline $\begin{array}{l}\text { C42HamP-F } \\
\text { C42HamP-R }\end{array}$ & chit42 & Promoter & T. hamatum & $\begin{array}{l}\text { atcgatcggtctggcattat } \\
\text { ttagtgaagtagacagcgtt }\end{array}$ & 54 & 1.6 \\
\hline $\begin{array}{l}\text { C42HamC-F } \\
\text { C42HamC-R }\end{array}$ & & Coding & T. hamatum & $\begin{array}{l}\text { tgcttgctgcgctgcagg } \\
\text { agaccttggtgttgatcaatg }\end{array}$ & 55 & 1.3 \\
\hline $\begin{array}{l}\text { C42HamC-F } \\
\text { C42HarC-R }\end{array}$ & & & T. harzianum & $\begin{array}{l}\text { tgcttgctgcgctgcagg } \\
\text { tcccagataccggcetcc }\end{array}$ & 66 & 1.0 \\
\hline $\begin{array}{l}\text { PRBHamP-F } \\
\text { PRBHamP-R }\end{array}$ & prb1 & Promoter & T. hamatum & $\begin{array}{l}\text { gataaggcgccggctacg } \\
\text { gcttcttgtgagggctgc }\end{array}$ & 60 & 0.8 \\
\hline $\begin{array}{l}\text { PRBAtrC-F } \\
\text { PRBAtrC-R }\end{array}$ & & Coding & $\begin{array}{l}\text { T. hamatum } \\
\text { T. harzianum }\end{array}$ & $\begin{array}{l}\text { agctttgctcccggctgtcc } \\
\text { ccaacaacgtgaggtgtagccatg }\end{array}$ & 55 & 1.2 \\
\hline $\begin{array}{l}\text { XBGHamP-F } \\
\text { XBGHamP-R }\end{array}$ & $x \operatorname{cog} 1.3-110$ & Promoter & T. hamatum & $\begin{array}{l}\text { tggttgacaacagtcatgtacc } \\
\text { tgtactgctgattaccatggc }\end{array}$ & 64 & $1.8^{\mathrm{a}}$ \\
\hline $\begin{array}{l}\text { XBGHamC-F } \\
\text { XBGHamC-R }\end{array}$ & & Coding & T. hamatum & $\begin{array}{l}\text { ggatctgctggattcctcac } \\
\text { gtagccaagttccactcgatg }\end{array}$ & 65 & 0.9 \\
\hline
\end{tabular}

a Gene fragment extends from $1 \mathrm{~kb} \mathrm{5'}$ to the translational start site to $800 \mathrm{bp}$ of the coding region.

were designed to a region approximately $50 \mathrm{bp}$ inside the LU592 prb1 DNA sequence. These were used to amplify the T. hamatum promoter and $3^{\prime}$ flanking region from a recircularized HindIII digest, according to standard inverse PCR protocols (Ochman et al 1990). Specific primers were designed to the extended sequence and used to amplify the promoter region (TABLE I). The lam1.3 homologue, $x b g 1.3-$ 110, was isolated from T. hamatum LU593 using a combination of inverse and degenerate PCR. Degenerate primers were based on regions of identity between the protein sequences of lam1.3 (accession number AJ002397) from $T$. harzianum T-Y and exg1 (accession number L48994) from Cochliobolus carbonum SB111. The degenerate primers XBGp394 (5'-A/TC/GA/C/TAAGCCA/C/TCAA/GTAC/ TGAG-3') and XBGp535 (5'-G/TCG/TA/G/TGTA/GTGA/ GACA/GTCCCA-3') were used to amplify a 500 bp fragment of xbg1.3-110 from T. hamatum LU593. Inverse primers IXBG-58 (5'-CCTTGACAAACAATGAATAACAG-3') and IXBG-423 (5'-GTCCTCATCGAGTGGAACTTG-3') were used to amplify flanking regions from a recircularized PvuII digest extending the sequence to $\sim 1.7 \mathrm{~kb}$. Degenerate primer XBGp61 (5'-AACGTC/TAAGGAC/TTACGGA/C/TGCG/ TAAG- $3^{\prime}$ ) was designed to a region $5^{\prime}$ to the $1.7 \mathrm{~kb} x b g 1.3-$ 110 sequence and used with the sequence specific primer XBGext-as (5'-TTATTTCGGTACTGCAACGGC-3') to amplify a further $550 \mathrm{bp}$ extending the sequence to $2.2 \mathrm{~kb}$. Inverse primers I-XBG4up (5'-TGTTAATTGCTGCCGTGTC GT-3') and I-XBG2down (5'-CGTGAATAGAACTGGCTCT G- $3^{\prime}$ ) amplified regions flanking the $2.2 \mathrm{~kb}$ sequence from a recircularized $N c o I$ digest extending the sequence to 3.8 $\mathrm{kb}$. Specific primers were designed and used to amplify the promoter and coding regions (TABLE I).

Using the primers in TABLE I, promoter and coding regions were amplified in an Eppendorf Mastercycler ${ }^{\circledR}$ Gradient PCR machine (Eppendorf-Netherler-Hinz GmbH) for sequence analysis and for use as probes in RNA analysis. Each $25 \mu \mathrm{L}$ PCR reaction contained $10 \mathrm{mM}$ Tris- $\mathrm{HCl} \mathrm{pH}$ 8.0, $50 \mathrm{mM} \mathrm{KCl}, 1.5 \mathrm{mM} \mathrm{MgCl}_{2}, 200 \mu \mathrm{M}$ each of dATP,
dCTP, dGTP and dTTP (Roche Molecular Biochemicals Ltd.), 10 pmol of each primer, $10 \mathrm{ng}$ of genomic DNA and 1.25 U Taq DNA polymerase (Roche Molecular Biochemicals Ltd.). Amplifications consisted of $5 \mathrm{~min}$ at $94 \mathrm{C}$, followed by 30 cycles of $30 \mathrm{~s}$ at $94 \mathrm{C}, 30 \mathrm{~s}$ at the annealing temperature indicated (TABLE I), and $1 \mathrm{~min}$ at $72 \mathrm{C}$, followed by $7 \mathrm{~min}$ at $72 \mathrm{C}$.

All gene fragments were ligated to pGEM $^{\circledR}-\mathrm{T}$ (Promega Corp., Madison, Wisconsin) (Appendix 7.4) as per manufacturer's instructions and transformed into E. coli strain INV $\alpha F^{\prime}$ (Invitrogen Corp.) using standard techniques (Sambrook et al 1989). Plasmid DNA was prepared using the Perfectprep ${ }^{\circledR}$ Plasmid Mini Kit (Eppendorf-Netheler-Hinz $\mathrm{GmbH}$ ) as per manufacturer's instructions. Two clones per transformation were sequenced in both directions (University of Auckland). Trichoderma hamatum LU593 sequences were deposited in GenBank with these accession numbers: ITS1-AY241456, chit42-AY258898, prb1-AY258899, xbg1.3110-AY269826.

Promoter sequence analysis.-To identify putative binding sites for regulators, promoter sequences were aligned with homologues from T. atroviride IMI206040, with common eukaryotic elements and with fungal specific motifs from other filamentous fungi using DNAman (Lynnon Biosoft). In addition, short identical motifs between the three promoters were identified through sequential alignments of 50 bp segments.

Substrate induction assays.-Submerged culture assays were performed as follows. A $100 \mathrm{~mL}$ flask containing $25 \mathrm{~mL}$ of half-strength potato-dextrose both $(\mathrm{PDB})$ and $2.5 \times 10^{8}$ conidia was incubated $14 \mathrm{~h}$ at $22 \mathrm{C}$ in the dark on a rotary shaker $(200 \mathrm{rpm})$. Mycelium was collected by centrifugation at $2000 \mathrm{~g}$ for $5 \mathrm{~min}$ at $4 \mathrm{C}$, transferred to minimal media (MM) ([0.2 g MgSO $\mathrm{g}_{4} \cdot 7 \mathrm{H}_{2} \mathrm{O}, 0.9 \mathrm{~g} \mathrm{~K}_{2} \mathrm{HPO}_{4}, 0.2 \mathrm{~g} \mathrm{KCl}, 1 \mathrm{~g}$ $\mathrm{NH}_{4} \mathrm{NO}_{3}, 2 \mathrm{mg} \mathrm{FeSO} \cdot \cdot 7 \mathrm{H}_{2} \mathrm{O}, 2 \mathrm{mg} \mathrm{ZnSO} \cdot 7 \mathrm{H}_{2} \mathrm{O}, 2 \mathrm{mg}$ $\mathrm{MnCl}_{2} \cdot 7 \mathrm{H}_{2} \mathrm{O}$ and $2 \mathrm{~g}$ asparagine per litre water; $\mathrm{pH}$ 5.5] [Carsolio et al 1994]) with $0.4 \%$ glycerol and incubated 12 


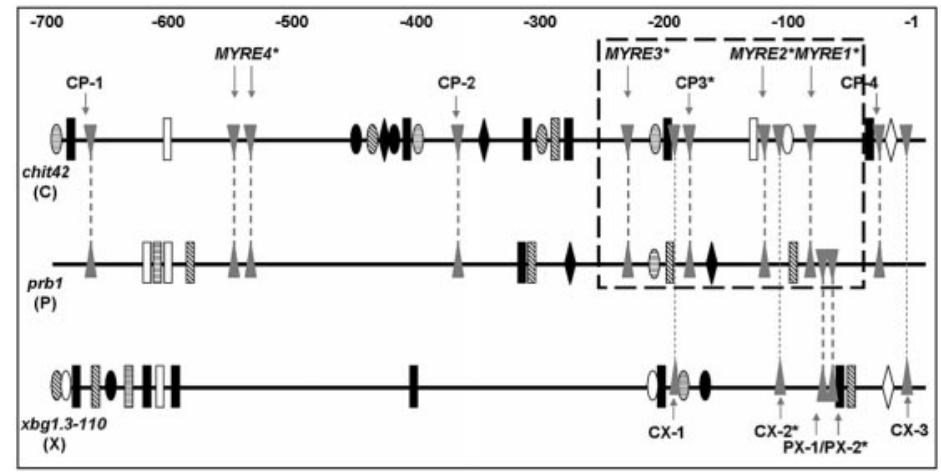

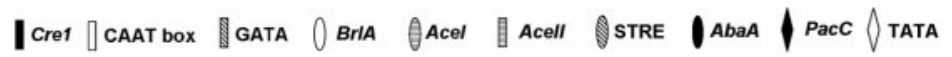

FIG. 1. T. hamatum LU593 chit42, prb1 and $x b g 1.3-110$ promoter sequences 700 bp $5^{\prime}$ to the transcription start point. Cre1 (5'SYGGRG3') binds the catabolite repressor protein (Lorito et al 1996), STRE (CCCCT) is a stress-response motif (Cortés et al 1998), AbaA and BrlA (5'CATTCY3', 5'MRAGGGR3') bind to regulators of light-induced sporulation (Andrianopoulos and Timberlake 1994, Chang and Timberlake 1992), AceI and AceII (5'AGGCA3', 5'GGCTAA3') are involved in induction of cellobiohydrolase genes in reponse to cellulose (Saloheimo et al 2000, Aro et al 2001), GATA (5'HGATAR3') binds to a regulator of nitrogen repression (Olmedo-Monfil et al 2002), PacC (5'GCCARG3') binds to the ambient pH regulator PacC (Denison2000). MYRE4-MYRE1 are postulated to be involved in mycoparasitism and were identified previously (Cortés et al 1998). CP (chit42 and prb1), CX (chit42 and xbg1.3-110) and PX (prb1 and xbg1.3-110) motifs were identified in this study: CP-1 (5'ATTAGAGCT3'), CP-2 (5'AACGTT3'), CP-3 (5'TTCTAG3'), CP-4 (5'TTGACT3'), CX-1 (5' GGAGAC3'), CX-2 (5'TGGGTT3'), CX-3 (5'TCGTGC3'), PX-1 (5'GAAATCG3'), PX-2 (5'ATTTAAG3').

* Conserved with T. atroviride IMI206040.

$\mathrm{h}$ under the previously described conditions. The mycelium again was collected, and the pellet was separated into five portions; one portion was snap frozen (day 0) and the other four were transferred to $2 \%$ glycerol $\mathrm{MM} \mathrm{pH} \mathrm{5.5,} \mathrm{or} \mathrm{MM}$ without glycerol (control). Mycelium was harvested at 24, 48, 72 and $96 \mathrm{~h}$ (days 1-4). The laminarin assay was conducted as above, except that after the second centrifugation step the pellet was separated into two portions; one portion was snap frozen in liquid $\mathrm{N}_{2}(0 \mathrm{~h})$ and the other transferred to $2 \%$ glycerol MM pH 5.5 with $0.5 \%$ laminarin (SIGMA: L-9634) or 2\% glycerol MM only (control). Mycelia were harvested at $48 \mathrm{~h}$ and snap frozen. All mycelial samples were stored at $-80 \mathrm{C}$ until processed. Each assay was replicated once.

Direct confrontation assay.-Direct confrontation assays were performed on agar plates covered with cellophane using a modification of the method of Carsolio et al (1994). Fungi were grown at $22 \mathrm{C}$ in the dark on minimal media (MM) agar with $0.2 \%$ glycerol.

RNA dot-blot analysis.-Total RNA was extracted (TRIzol, Invitrogen) and $20 \mu \mathrm{g}$ transferred to Hybond $\mathrm{N}+$ nylon membrane (Amersham) with a Bio-Dot Microfiltration Apparatus (Bio-Rad). Coding region fragments of chit42 and prb1 from T. hamatum and T. harzianum and xbg1.3-110 from $T$. hamatum were used as probes in northern hybridizations. Chemiluminescent detection was performed using the ECL Direct Nucleic Acid Labelling and Detection System (Amersham).
RESULTS

Upstream regulatory sequence analysis of three mycoparasitism-related genes.-A common approach to sequence analysis has been comparison of gene homologues in related species or coregulated genes in the same species. Both approaches were taken in this study. Three mycoparasitism-related genes were sequenced from a T. hamatum biocontrol agent. Transcription start points (TSP) and exon/intron boundaries were assigned on the basis of conservation with related sequences. The endochitinase chit42 was compared to the T. hamatum (Tam-61) sequence deposited on GenBank (accession number U88560), sharing $99.84 \%$ nucleotide and $99.41 \%$ amino acid identity. Trichoderma hamatum prb1 shared $88.75 \%$ nucleotide identity across the coding region and 96.4\% amino acid identity with $T$. atroviride prb1 (accession number M87518) and xbg1.3-110 shared $83.55 \%$ identity in the coding region and $90.18 \%$ amino acid identity with $T$. harzianum lam 1.3 (xbg1.3-110) (AJ002397).

Sequence analysis of the promoter regions identified numerous putative regulatory motifs previously reported in other fungal genes, including Trichoderma mycoparasitism-related genes (FIG. 1). Regions were aligned with available promoter sequences from the homologous T. atroviride ech42 (843 bp, accession number Z803580) and prb1 (1274 bp, Alfredo 


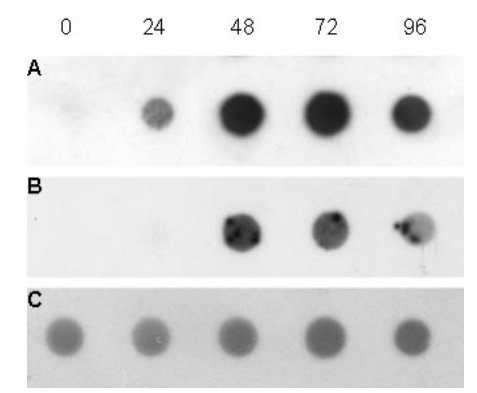

FIG. 2. Expression of T. hamatum LU593 chit42 and prb1 in MM $+2 \%$ glycerol submerged cultures. Sampling times in hours are shown above the figure. A, B, C RNA dot-blot analysis of $20 \mu \mathrm{g}$ total RNA. A chit42. B prb1. C ITS1 rRNA.

Herrera-Estrella, pers comm) to determine which motifs were conserved in both biocontrol species. Only $58 \mathrm{bp} 5^{\prime}$ to the TSP from T. harzianum lam 1.3 (xbg1.3-110) (accession number AJ002397) was available for alignment with $x b g 1.3-110$. Approximately half the motifs identified in chit 42 and prb1 were conserved with their T. atroviride homologues. Comparative alignments of the promoter regions between the three T. hamatum genes revealed that chit 42 and prb1 shared more sequence identity than either with xbg1.3-110. In addition, while the putative mycoparasitic motifs MYRE4-MYRE1 (Cortés et al 1998) were conserved in chit42 and prb1, none were present in xbg1.3-110.

Differential expression of chit42, prb1 and xbg1.3110.- Strong sequence identity between the regulatory regions of chit 42 and prb1 led to the prediction that they shared common regulatory pathways. To test this hypothesis, gene expression patterns of chit42, prb1 and xbg1.3-110 were analyzed in the presence of the simple carbon source glycerol. chit42 and prb1 were induced strongly at $48 \mathrm{~h}$, decreasing at $96 \mathrm{~h}$, in $T$. hamatum grown in minimal media broth with $2 \%$ glycerol (FIG. 2), whereas in T. harzianum no expression of chit42 or prb1 was observed. In MM without glycerol conidia germinated and died (data not shown) whereas in $2 \%$ glycerol, cultures increased in size throughout the experiment, indicating metabolism of the available carbon. No expression of $x b g 1.3-110$ was detected, however strong expression was observed in $2 \%$ glycerol MM with $0.5 \%$ laminarin, a common substrate for $\beta-1,3$-glucanases, demonstrating the gene to be active (FIG. 3).

Expression patterns of T. hamatum chit42, prb1 and $x b g 1.3-110$ further were analyzed during confrontation with the plant pathogen Sclerotinia sclerotiorum (FIG. 4). Both chit42 and prb1 were expressed moderately upon physical contact with $S$. sclerotiorum, however no xbg1.3-110 expression was detected at

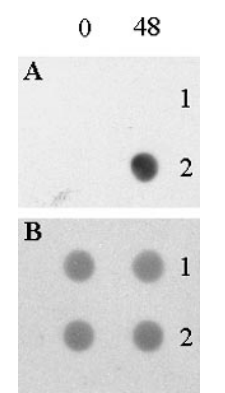

FIG. 3. Expression of T. hamatum LU593 xbg1.3-110 in laminarin submerged cultures. Sampling times in hours are shown above the figure. A, B, RNA dot-blot analysis of 20 $\mu \mathrm{g}$ total RNA from LU593 grown in MM $+2 \%$ glycerol (1) or $\mathrm{MM}+2 \%$ glycerol $+0.5 \%$ laminarin (2). A xbg1.3-110. B ITS1 rRNA.

any sampling interval. Low expression of chit42 and prb1 also was observed in the T. hamatum versus $T$. hamatum treatment.

\section{DISCUSSION}

Various environmental inducers of Trichoderma mycoparasitism-related genes have been postulated on

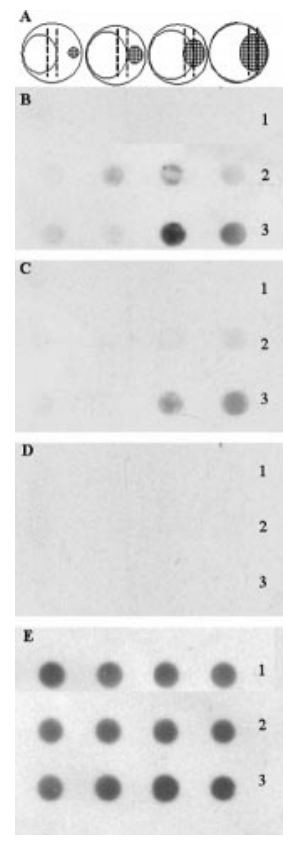

FIG. 4. Expression of T. hamatum LU593 chit42 and prb1 during confrontation with $S$. sclerotiorum G1. A. Diagrammatic representation of assay and sampling zones. Outer circle represents the plate, the inner circles represent $T$. hamatum (open circle) and S. sclerotiorum (checkered circle) and the dashed lines the sampling zones. B, C, D, E. RNA dot-blot analysis of $20 \mu \mathrm{g}$ total RNA from LU593 alone (1), LU593 v LU593 (2) and LU593 v S. sclerotiorum G1 (3) at the sampling intervals above. B. chit42. C. prb1. D. xbg1.3-110. E. ITS1 rRNA. 
the basis of sequence, northern and protein analysis in T. atroviride and T. harzianum. In this study, three mycoparasitism-related gene homologues from T. hamatum, a lesser known biocontrol species, were analyzed with reference to sequence structure of their promoter regions and their expression in response to a simple carbon source (glycerol) and complex carbon source in the form of the plant pathogen Sclerotinia sclerotiorum.

Identification of regulatory motifs in the promoter region might provide evidence for common regulatory pathways. A detailed summary of the motifs identified in the $T$. hamatum promoter region are shown in FIG. 1. Of the three genes, chit42 and prb1 shared the most sequence identity in the promoter/ enhancer region. Strong conservation of the four putative binding sites (MYRE1-MYRE4) for a global inducer of mycoparasitism-related genes that was identified in T. atroviride chit42 (ech42) and prb1 (Cortés et al 1998) is evident. These exact motifs were conserved in the $T$. hamatum homologues yet absent in T. hamatum xbg1.3-110. In T. hamatum MYRE3, CP3, MYRE2 and MYRE1 formed a highly conserved cluster proximal to the transcription start site that spanned exactly 142 bp in both chit42 and prb1. The 6 bp identity CP3 also was conserved in T. atroviride, however, it had not been identified by Cortés et al (1998). In T. hamatum, each motif within the cluster lay exactly the same distance apart in both chit42 and prb1. The conservation of the regulatory elements MYRE1-MYRE3 and CP3 in the T. hamatum genes chit42 and prb1 suggested that these genes more likely are to be co-expressed during mycoparasitism.

In its simplest form mycoparasitism is the acquisition of carbon from another fungus. In this study glycerol was used as the simple carbon source in a substrate assay. Strong gene expression of Trichoderma mycoparasitism-related genes in minimal media supplemented with elevated glycerol has not been reported before. No expression of ech 42 and only weak expression of prb1 from $T$. atroviride has been observed previously under these conditions (Cortés et al 1998), and no chit42 or prb1 expression was detected from T. harzianum grown under the same conditions (this study). The results presented here suggest that in T. hamatum chit42 and prb1 might be coregulated by a metabolic pathway that responds to elevated glycerol. Because all three genes have been implicated in cellular differentiation and growth, it also is possible that up-regulation of LU593 chit42 and prb1 was in response to growth-stage regulation of expression not elevated glycerol. However, the very closely related $T$. harzianum showed no gene expression of homologues at any time, despite undergoing parallel growth and differentiation (data not shown).
For this reason it is unlikely that growth-stage-specific regulation was the cause of the increased chit42 and prb1 expression. Mycoparasitism and glycerol utilization are examples of alternative carbon source metabolic pathways. Other nonglucose carbon sources, such as V8 juice, directly enhance chitinase protein activity in both $T$. atroviride $(\mathrm{P} 1)$ and $T$. virens (Tronsmo and Harman 1992). In the presence of both chitin and V8 juice, chitinase production followed similar patterns in both isolates. However, T. virens produced substantially lower yields of extracellular chitinases to $T$. atroviride, suggesting differential regulation. The $T$. hamatum response in minimal media amended with high glycerol may represent an alternative carbon induction pathway absent or not active in other Trichoderma species. These data support the results of the sequence analysis, where the chit42 and prb1 promoter regions both included the MYRE4-MRYE1 elements and showed greater similarity to each other than to $x \operatorname{bg} 1.3-110$, in which MYRE4-MYRE1 were absent.

It is likely that several other events play a role in the induction of mycoparasitism including recognition, chemical secretion by the pathogen and defence or evasion responses. To further study the response of the mycoparasitism genes from T. hamatum in a more realistic situation, confrontation against plant pathogens in an agar plate assay was used. The T. hamatum BCA used in this study had demonstrated previously high biocontrol activity toward Sclerotinia diseases in the field (Rabeendran 2000) and mycoparasitism of S. sclerotiorum by LU593 has been observed in vitro (data not shown). For these reasons the plant pathogen $S$. sclerotiorum was used in all confrontation assays. Expression analysis of chit42, prb1 and $x \operatorname{bg} 1.3-110$ in response to co-inoculation with the plant pathogen $S$. sclerotiorum confirmed predictions made on co-expression by promoter sequence analysis and the glycerol assay. As predicted by this sequence analysis chit42 and prb1 shared expression patterns under all test conditions. The lack of $x b g 1.3-$ 110 expression during confrontation with S. sclerotiorum and in response to glycerol demonstrated that it did not share the same expression patterns as chit42 and prb1 and did not play a role in initial mycoparasitism of $S$. sclerotiorum. These data support the results of the sequence analysis, where the chit42 and prb1 promoter regions both included the MYRE1-MRYE4 and CP3 elements and showed greater similarity to each other than to $x$ bg 1.3-110, in which these elements were absent. This suggests that similarity between promoter regions of different genes can predict co-expression.

Weak expression of chit42 and prb1 was observed in the T. hamatum-T. hamatum contact and is prob- 
ably the result of a reduced nutrient availability. In the $T$. hamatum alone controls expression of both chit42 and prb1 was undetectable. In T. atroviride there was no increase in prb1 relative to $T$. atroviride alone controls and ech42 expression barely was detectable, which suggested expression during confrontation with the pathogen $R$. solani was parasitism specific (Cortés et al 1998). In T. hamatum expression of chit42 and prb1 during confrontation with S. sclerotiorum is due likely in part to a nutrient-regulated factor, however, the fungal biomass of the confrontation was less than that of the self-self controls. Therefore, the increase in expression during confrontation is likely to be primarily the result of mycoparasitism rather than increased nutrient depletion.

These studies also demonstrated that expression of different mycoparasitism-related genes in Trichoderma species is highly variable. Extracellular secretion of variable enzymes profiles between biocontrol strains of $T$. harzianum have been observed in response to polysaccharides and host cell walls (Elad et al 1982, Mach et al 1999). This study found interspecies variation in expression of three mycoparasitismrelated genes. In addition, it has been suggested during confrontation T. atroviride Prb1 might release an inducer from the host that induces ech 42 expression (Cortés et al 1998). This is unlikely to be true for $T$. hamatum because chit42 is expressed earlier and stronger than prb1. The regulation of genes encoding enzymes that have been implicated in mycoparasitism is clearly complex and, in many instances, species-specific pathways occur. However, this work has shown that conservation of regulatory motifs can predict coregulation and provide information on metabolic pathways likely to be conserved among Trichoderma species. It is interesting to note that all MYRE elements identified in T. atroviride were conserved in T. hamatum, whereas only half the putative transcription factor motifs identified in this study were conserved between both species.

Mycoparasitism is simply an alternate means of carbon assimilation, characterized by catabolite repression and induction during carbon starvation. When carbon deprived, alternative pathways are turned on in response to environmental stimulators, such as presence of another fungus or easily metabolizable carbon source. Genes implicated in mycoparasitism are regulated differentially among Trichoderma species in a carbon-source-dependent fashion. Knowledge of carbon sources that up-regulate mycoparasitism-related genes is likely to have implications for the design of Trichoderma inoculants and might improve reliability of commercial biocontrol agents.

\section{ACKNOWLEDGMENTS}

We would like to thank Professor Alfredo Herrera-Estrella for kindly providing the T. atroviride IMI204060 prb1 promoter sequence. This work was financed by the New Zealand Foundation for Research, Science and Technology.

\section{LITERATURE CITED}

Andrianopoulos A, Timberlake WE. 1994. The Aspergillus nidulans abaA gene encodes a transcriptional activator that acts as a genetic switch to control development. Mol Cell Biol 14:2503-2515.

Aro N, Saloheimo A, Ilmén M, Penttilä M. 2001. ACEII, a novel transcriptional activator involved in regulation of cellulase and xylanase genes of Trichoderma reesei. J Biol Chem 276:24309-24314.

Benítez T, Limón C, Delgado-Jarana J, Rey M. 1998. Glucanolytic and other enzymes and their genes. In: Harman GE, Kubicek CP, eds. Trichoderma and Gliocladium, vol 2: enzymes, biological control and commercial application. London: Taylor \& Francis. p 101-128.

Carsolio C, Gutiérrez A, Jiménez B, van Montagu M, Herrera-Estrella A. 1994. Characterization of ech-42, a Trichoderma harzianum endochitinase gene expressed during mycoparasitism. Proc Natl Acad Sci USA 91: 10903-10907.

_- Benhamou N, Haran S, Cortés C, Gutiérrez A, Chet I, Herrera-Estrella A. 1999. Role of Trichoderma harzianum endochitinase gene, ech42, in mycoparasitism. Appl Environ Microbiol 65:929-935.

Chang YC, Timberlake WE. 1992. Identification of Aspergillus brlA response elements (BREs) by genetic selection in yeast. Genet 133:29-38.

Chernin L, Chet I. 2002. Microbial enzymes in the biocontrol of plant pathogens and pests. In: Burns RG, Dick RP, eds. Enzymes in the Environment: Activity, Ecology and Applications. New York: Marcel Dekker. p 171-226.

Cohen-Kupiec R, Broglie KE, Friesem D, Broglie RM, Chet I. 1999. Molecular characterization of a novel $\beta-1,3-\mathrm{ex}-$ oglucanase related to mycoparasitism of Trichoderma harzianum. Gene 226:147-154.

Cortés C, Gutierrez A, Olmedo V, Inbar J, Chet I, HerreraEstrella A. 1998. The expression of genes involved in parasitism by Trichoderma harzianum is triggered by a diffusible factor. Mol Gen Genet 260:218-225.

De las Mercedes Dana M, Limón MC, Mejías R, Mach RL, Benítez T, Pintor-Toro JA, Kubicek CP. 2001. Regulation of chitinase 33 (chit33) gene expression in Trichoderma harzianum. Curr Genet 38:335-342.

Denison SH. 2000. pH regulation of gene expression in fungi. Fungal Genet Biol 29:61-71.

Donzelli BGG, Lorito M, Scala F, Harman GE. 2001. Cloning, sequence and structure of a gene encoding an antifungal glucan 1,3- $\beta$-glucosidase from Trichoderma atroviride (T. harzianum). Gene 277:199-208.

Elad Y, Chet I, Henis Y. 1982. Degradation of plant pathogenic fungi by Trichoderma harzianum. Can J Microbiol 28:719-725.

Flores A, Chet I, Herrera-Estrella A. 1997. Improved bio- 
control activity of the proteinase-encoding gene prb1. Curr Genet 31:30-37.

Jones EE, Stewart A. 2000. Selection of mycoparasitise of sclerotia of Sclerotinia sclerotiorum isolated from New Zealand soils. NZ J Crop Hort Sci 28:105-114.

Kubicek CP, Penttilä ME. 1998. Regulation of production of plant polysaccharide degrading enzymes by Trichoderma. In: Harman GE, Kubicek CP, eds. Trichoderma and Gliocladium, vol 2: enzymes, biological control and commercial application. London: Taylor \& Francis. p 49-72.

—, Mach RL, Peterbauer CK, Lorito M. 2001. Trichoderma: from genes to biocontrol. J Plant Pathol 83:1123.

Kullnig CM, Krupica T, Woo SL, Mach RL, Rey M, Benítez T, Lorito M, Kubicek CP. 2001. Confusion abounds over identities of Trichoderma biocontrol isolates. Mycol Res 105:770-772.

Lieckfeldt E, Cavignac Y, Fekete C, Börner T. 2000. Endochitinase gene-based phylogenetic analysis of Trichoderma. Microbiol Res 155:7-15.

Lorito M, Mach RL, Sposato P, Strauss J, Peterbauer CK, Kubicek CP. 1996. Mycoparasitic interaction relieves binding of the Cre1 carbon catabolite repressor protein to promoter sequences of the ech42 (endochitinase-encoding) gene in Trichoderma harzianum. Proc Natl Acad Sci USA 93:14868-14872.

- 1998. Chitinolytic enzymes and their genes. In: Harman GE, Kubicek CP, eds. Trichoderma and Gliocladium, vol 2: enzymes, biological control and commercial application. London: Taylor \& Francis. p 73-100.
Mach RL, Peterbauer CK, Payer K, Jaksits S, Woo SL, Zeilinger S, Kullnig CM, Lorito M, Kubicek CP. 1999. Expression of two major chitinase genes of Trichoderma atroviride (T. harzianum $\mathrm{P} 1)$ is triggered by different regulatory signals. Appl Environ Microbiol 65:18581863.

Ochman H, Medhora MM, Garza D, Hartl DL. 1990. Amplification of flanking sequences by inverse PCR. In: Innis MA, Gelfand DH, Sninsky JJ, White TJ, eds. PCR protocols: a guide to methods and applications. San Diego: Academic Press. p 219-227.

Olmedo-Monfil V, Mendoza-Mendoza A, Gómez I, Cortés C, Herrera-Estrella A. 2002. Multiple environmental signals determine the transcriptional activation of the mycoparasitism related gene prb1 in Trichoderma atroviride. Mol Genet Genomics 267:703-712.

Rabeendran N. 2000. Biological control of Sclerotinia diseases of vegetables. [Doctoral thesis]. Lincoln University, Canterbury, New Zealand.

Saloheimo A, Aro N, Ilmén M, Penttilä M. 2000. Isolation of the ace1 gene encoding a Cys2-His2 transcription factor involved in regulation of activity of the cellulase promoter cbh1 of Trichoderma reesei. J Biol Chem 275: 5817-5825.

Sambrook J, Fritsch EF, Maniatis T. 1989. Molecular Cloning: A Laboratory Manual. 2nd ed. Cold Spring Harbor, NY: Cold Spring Harbor Laboratory Press.

Tronsmo A, Harman GE. 1992. Coproduction of chitinolytic enzymes and biomass for biological control by Trichoderma harzianum on media containing chitin. Biol Control 2:272-277. 